\title{
PENGEMBANGAN MOTIF BORDIR KERANCANG TASIKMALAYA DENGAN SOFTWARE JBATIK
}

\author{
The Development of Tasikmalaya Kerancang Embroidery Motif Through jBatik \\ Software
}

Widia Nur Utami Bastaman dan Tsanny Noer Intan Fadliani

Telkom University, J. Telekomunikasi No.1 Terusan Buah Batu, Bandung

\begin{tabular}{|c|c|}
\hline \multicolumn{2}{|l|}{ Korenspondesi Penulis } \\
\hline Email : widianur@telkomuniversity.ac.id & : 09 Juni 2020 \\
\hline & : 09 Juni 2020 \\
\hline
\end{tabular}

Kata kunci: bordir kerancang, , jBatik, tasikmalaya

Keywords: kerancang embroidery, jBatik, tasikmalaya

\section{ABSTRAK}

Kota Tasikmalaya adalah salah satu kota penghasil beragam produk kerajinan, salah satunya adalah produk bordir kerancang. Saat ini perkembangan motif dan produk bordir kerancang Tasikmalaya sudah semakin modern, kondisi ini memberikan peluang baik untuk menerapkan teknologi baru yaitu software jBatik dalam proses perancangannya. Software ini akan membantu merancang komposisi motif sesuai dengan prinsip fractal pada rumus matematika. Tujuan penelitian ini adalah untuk menghasilkan varian produk baru dan memberikan alternatif perancangan desain komposisi motif bordir kerancang Tasikmalaya. Salah satu produk unggulan bordir kerancang adalah kebaya, sehingga melalui penelitian ini diharapkan dapat menambah nilai estetik serta nilai ekonomi kebaya bordir kerancang Tasikmalaya. Metode penelitian yang dilakukan terdiri dari dua tahapan, tahapan yang pertama adalah pengumpulan data melalui studi literatur, observasi lapangan, serta wawancara. Lalu tahapan berikutnya adalah metode eksplorasi desain komposisi motif menggunakan software jBatik dan penerapannya pada pola kebaya. Tema perancangan yang diangkat berkaitan dengan persilangan kebudayaan Indonesia, Belanda, dan Cina yang erat dengan sejarah perkembangan kebaya kerancang atau lebih dikenal sebagai kebaya encim di Indonesia. Hasil penelitian ini berupa desain komposisi motif bordir kerancang yang terinspirasi dari motif bunga chrysanthenum, bunga lotus, dan phoenix yang berwarna bold atau terang, namun dikombinasikan dengan warna lembut sesuai dengan karakter kebaya kerancang. Komposisi motif diterapkan pada purwarupa produk dengan ukuran 1:1.

\section{ABSTRACT}

Tasikmalaya is one of the cities producing various handicraft products, one of which is kerancang embroidery products. Currently, the development of Tasikmalaya kerancang embroidery motifs and products are getting more modern; this condition provides a good opportunity to apply new technologies, namely jBatik software, in the design process. This study aims to produce new product variants and provide alternative motif composition design of kerancang embroidery. One of the featured products of kerancang embroidery is kebaya. Hopefully, this research can add the aesthetic and economic value of the Tasikmalaya kerancang embroidery's kebaya. The research method consists of two stages; the first stage is data collection through literature, field observations, and interviews. The next stage is the exploration method of motif composition design using jBatik software and its application to the kebaya pattern. The design theme is related to the crossbreeding of Indonesian, Dutch and Chinese cultures, which is closely related to the history of the kebaya kerancang design or better known as kebaya encim. The motif's composition is applied to the prototype of the kebaya kerancang with a size of 1: 1. 


\section{PENDAHULUAN}

Tasikmalaya adalah salah satu kota besar di provinsi Jawa Barat yang dikenal sebagai kota penghasil beragam kerajinan. Salah satu jenis kerajinannya yang terkenal adalah bordir. Bordir sudah menjadi komoditas industri perdagangan dan menjadi daya tarik pariwisata kota Tasikmalaya sejak lama. Produk bordir Tasikmalaya sudah dipasarkan ke seluruh kota besar di Indonesia juga mancanegara. Hingga kini industri bordir Tasikmalaya sudah menyerap sebanyak 31.325 orang, yang tersebar pada 2.728 unit usaha. Tasikmalaya juga dikenal dengan julukan Kota Santri, membuat karakter motif bordir dan produk bordir yang dirancang oleh pengrajin Tasikmalaya memiliki karakter khas yang bersifat religi. Seperti pada motif Sukapura, yang merupakan motif flora khas kota Tasikmalaya berupa motif flora (Nero, Sofianto, Sutirman, \& Suganda, 2019). Pengembangan motif bordir Tasikmalaya disesuaikan dengan kaidah Islam yang melarang untuk menerapkan motif makhluk bernyawa seperti manusia dan hewan (Putrie \& Hosiah, 2012). Motif yang umum dijumpai adalah motif naturalis flora, geometris, dan dekoratif. Ada 10 jenis teknis bordir yang umum digunakan, namun salah satu yang banyak dikembangkan adalah teknik bordir kerancang. Sedangkan untuk aplikasi bordir pada produk, masih didominasi oleh produk sandang dan pelengkap muslimah seperti baju gamis, baju koko, mukena, dan tas (Loita \& Husen, 2018).

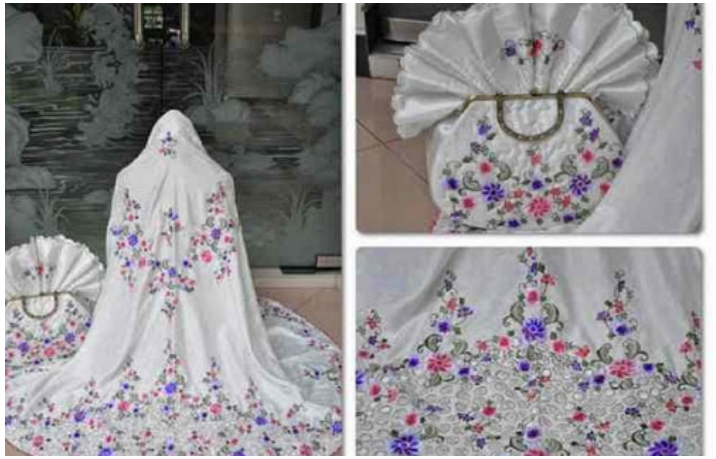

Gambar 1. Contoh produk bordir kerancang Tasikmalaya

Di sisi lain, seiring dengan perkembangan zaman dan kebutuhan pasar, perlahan-lahan motif serta produk aplikasi bordir Tasikmalaya berkembang menjadi lebih global (Nero et al., 2019). Walaupun tetap fokus dalam mengembangkan produk sandang dan pelengkapnya, namun motif, tema, warna, dan komposisi motif yang berkembang, menjadi lebih modern dan variatif (Darusman, 2016).

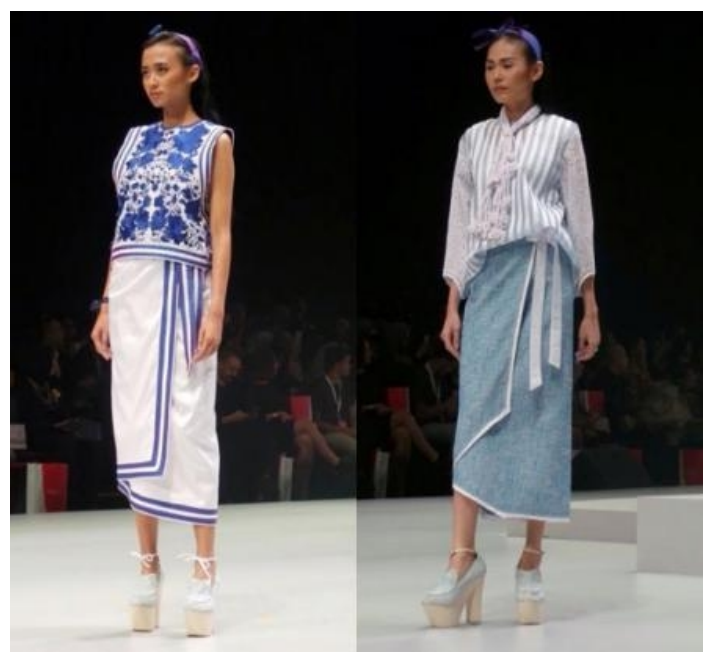

Gambar 2. Koleksi bordir Tasikmalaya modern bertajuk 'Krancang"karya Rika Mulle

Keterampilan bordir di Tasikmalaya diturunkan secara turun-menurun kepada generasi selanjutnya melalui proses pendidikan informal dari keluarga, tetangga, dan masyarakat sekitar. Proses ini dikenal 
clKh Dinamika Kerajinan dan Batik: Majalah Ilmiah. Vol. 37 No. 2, Desember 2020, hal. 135 - 146

dengan istilah pendidikan indeginius.

Dengan terjaganya proses regenerisasi melalui pendidikan indeginius, diharapkan kekayaan intelektual mengenai keterampilan bordir dapat tetap lestari (Chen \& Zhang, 2018). Diberikannya nilai tambah (added value) pada produk kerajinan yang memiliki nilai kearifan lokal, membuatnya mampu untuk bertahan lebih lama, sehingga tanpa peran dari pelaku, praktisi, akademisi, dan pemerintah, sangat mungkin industri bordir Tasikmalaya tidak akan banyak berkembang (Darusman, 2016).

Dewasa ini, di luar kota Tasikmalaya sendiri, bordir kerancang mulai banyak dikembangkan dengan berbagai metode baru, di antaranya dengan memanfaatkan software desain untuk membantu pengembangan bentuk motif dan komposisi motif. Salah satu software desain yang berpotensi untuk diterapkan adalah software jBatik. Software jBatik merupakan software untuk menciptakan desain batik dengan menggunakan rumus fractal (Hariadi, Lukman, \& Destiarmand, 2013). Fractal merupakan cabang ilmu matematika yang mempelajari tentang perulangan dan kesamaan yang biasanya dihasilkan dengan cara mengulang sebuah komposisi (Heurteaux \& Jaffard, 2007).

Berdasarkan hasil wawancara dengan $\mathrm{M}$. Lukman (Fadliani, 2017) selaku Chief Design Officer Piksel, perusahaan pengembang software jBatik, hingga saat ini penggunaan software jBatik masih sebatas diaplikasikan pada proses perancangan motif dan komposisi untuk beragam kain batik dan kain ulos saja. Karakter komposisi motif batik yang terbentuk karena pengulangan modular motif memiliki karakter yang sama dengan motif bordir pada umumnya, sehingga berpeluang untuk dikembangkan melalui software ini (Fadliani, 2017).

Pemanfaatan teknologi baru tersebut, diharapkan dapat menciptakan inovasi dan juga menarik minat anak muda khususnya generasi penerus industri bordir Tasikmalaya untuk menerapkannya dalam proses perancangan. Potensi kearifan lokal dipadukan dengan teknologi tepat guna dalam industri kreatif dewasa ini dapat dimanfaatkan untuk menunjang penciptaan seni kreatif dan inovatif sesuai dinamika zaman. Dalam hal ini adalah pengembangan industri bordir Tasikmalaya, sehingga industri tersebut dapat semakin maju dan mampu mengikuti zaman (Yoga \& Eskak, 2015).

\section{Bordir}

Bordir sudah berkembang di Tasikmalaya sejak lama, seiring dengan berkembangnya perusahaan mesin jahit Singer yang mulai mempekerjakan masyarakat Indonesia pada tahun 1920-an. Salah satu pekerja tersebut kemudian memutuskan kembali ke daerah asal dan merintis usaha bordir. Industri ini sempat meredup saat awal kemerdekaan karena konflik DI/TII pada tahun 1955 di Tasikmalaya. Namun setelah konflik mereda para pemuda yang merantau ke Jakarta menjual keterampilannya pada pengusaha Cina, kembali ke Tasikmalaya dan membawa banyak pesanan bordir. Daerah tersebut kini dikenal sebagai Sentra Bordir Kawalu dan bordir terus berkembang ke seluruh kota Tasikmalaya hingga saat ini. Pengaruh Jawa, Hindu-Budha, Islam, dan Cina akhirnya membentuk karakter motif bordir Tasikmalaya (Nero et al., 2019). Walaupun dalam perkembangannya, unsur 
clKh Dinamika Kerajinan dan Batik: Majalah Ilmiah. Vol. 37 No. 2, Desember 2020, hal. 135 - 146

religi yang paling mendominasi mengingat julukan Kota santri lekat dengan kota Tasikmalaya hingga kini.

Sejarah mulai berkembangnya bordir dan terbentuknya sentra kerajinan di kota Tasikmalaya sudah dibahas dalam beberapa penelitian. Dalam penelitian (Loita \& Husen, 2018) didokumentasikan bahwa teknik bordir yang populer diaplikasikan di Tasikmalaya adalah teknik Tutupan, teknik Seret, teknik Semprot, teknik Cakruk/Garas, teknik Uter Bebas/Cacing Liar, teknik Gacruk/Blok, teknik Bulu Kusut, dan teknik Kerancang. Salah satu teknik yang paling banyak dipalikasikan pada produk adalah teknik kerancang. Teknik kerancang merupakan salah satu teknik menghias permukaan kain dengan benang mengikuti motif tertentu atau membuat bulatan atau bidang-bidang kecil, yang kemudian bagian dari bidang tersebut yang tidak terkena bordir akan dilubangi dengan cara digunting atau disolder (Yolanda \& Efi, 2019). Ada berbagai teknik pengembangan bordir kerancang yang dapat diaplikasikan pada produk sandang dan pelengkapnya (Yuliarma, 2016).

Mengenai proses pengerjaannya, umumnya di kota Tasikmalaya masih dilakukan secara manual untuk pesanan terbatas dan dilakukan secara komputerisasi untuk pesanan masal. Untuk bordir komputer, software yang digunakan adalah Wilcom EMB Studio, yaitu penggabungan software Wilcom dan Corel Draw X5. Belum ada penggunaan software desain lainnya yang umum digunakan dalam proses perancangan (Loita \& Husen, 2018).

Kerajinan bordir Tasikmalaya kini telah berubah menjadi industri kreatif tanpa kehilangan ciri budaya asalnya. Nilai kearifan lokal yang terkandung dalam industri ini menjadi nilai tambah pada setiap produknya. Proses regenerasinya yang sudah lama membuat industri ini semakin kuat (Darusman, 2016).

Seiring dengan berkembangnya bordir kota Tasikmalaya dan kesiapannya menerima pengaruh modern, belum ada penelitian yang fokus menganalisa proses perancangan motif bordir dan komposisi motif bordir, serta proses perancangannya yang melibatkan software baru yaitu jBatik. Merujuk pada hal tersebut, penelitian ini memiliki peluang besar untuk diteliti lebih lanjut.

\section{Kebaya Kerancang}

Salah satu produk fashion yang banyak mengaplikasikan bordir kerancang adalah kebaya. Kebaya adalah pakaian tradisional perempuan Indonesia. Kebaya kerancang adalah satu jenis kebaya yang populer, umumnya kebaya ini dikenal dengan sebutan kebaya nyonya atau kebaya encim, sebutan untuk wanita Tionghoa terhormat. Kebaya ini digunakan sebagai penanda status tinggi pada zamannya (Lee, 2016).

Ciri khas dari kebaya ini adalah teknik dekorasi bordir yang digunakannya, khususnya bordir kerancang. Bordir inilah yang menjadi salah satu nilai tambah dari kebaya tersebut, selain karena keindahan motifnya juga karena bordirnya dibuat secara manual. Motifnya secara umum terinspirasi dari kebudayaan Cina yaitu motif-motif geometris, tumbuhan, dan hewan. Jenis tumbuhan yang biasa diangkat sebagai inspirasi adalah bunga chrysanthenum, bunga lotus, bunga mawar, dan bunga melati. Lalu untuk hewan, banyak yang terinpsirasi dari merak, 
clKh Dinamika Kerajinan dan Batik: Majalah Ilmiah. Vol. 37 No. 2, Desember 2020, hal. 135 - 146

phoenix, dan naga. Semua mencerminkan simbol tinggi dan kebahagiaan dalam hidup menurut filosofi Cina (Gumulya \& Octavia, 2017).

Kebaya kerancang merupakan produk hasil persilangan kebudayaan Indonesia, Belanda, dan Cina. Kebudayaan Indonesia tampak dari shape kebaya itu sendiri, warna-warna kebaya umumnya menyerap kebudayaan Belanda, dan desain bordir banyak yang terinspirasi dari kebudayaan Cina. Warna-warna Belanda (Eropa) yang dianggap mencerminkan status tinggi adalah warna putih dan warna-warna lembut. Hal ini berkebalikkan dengan nilai yang dianut oleh kebudayaan Cina yang biasanya ditunjukkan dengan warna bold yang cerah. Karena warna putih menandakan suasana berkabung atau berduka. Persilangan ini akhirnya membuahkan desain kebaya baru yang menggabungkan warna lembut namun memiliki warna motif yang bold atau terang (Lukman, Piliang, \& Sunarto, 2013).

\section{Software jBatik}

jBatik adalah software untuk membuat desain motif batik dengan menggunakan rumus fractal, yaitu salah satu ilmu matematika yang mempelajari proses pengulangan (Heurteaux \& Jaffard, 2007). Dengan software jBatik pengrajin dapat membuat modular dan komposisi motif batik baru dalam berbagai varian. Fitur yang ditawarkan adalah membuat kemudahan dalam lengkungan, perbedaan jarak, serta perubahan ukuran secara presisi.

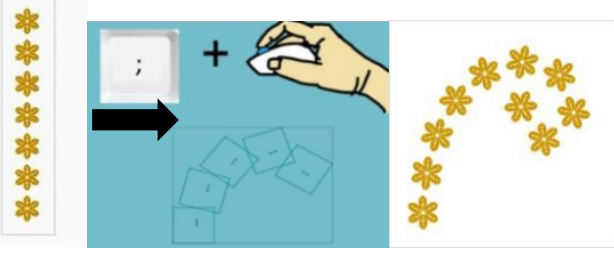

Gambar 3. Salah satu fitur untuk mengatur lengkungan dalam softwarejBatik

Software jBatik terdiri dari dua jenis yaitu jBatik Basic dan jBatik Pro, yang memiliki kelebihannya masing-masing. Software jBatik Basic digunakan untuk membuat motif 2D dan komposisi motif dengan mengembangkan modular motif yang sudah disediakan oleh software jBatik. Sedangkan software jBatik Pro, selain bisa membuat motif $2 \mathrm{D}$, juga bisa menghasilkan motif 3D. Motif ini dapat memiliki ketebalan, dan dapat dilihat dari berbagai sisi, tampak depan, tampak belakang, tampak kiri, tampak kanan, tampak atas, dan tampak bawah. Sehingga motif yang dihasilkan dapat lebih variatif dan dinamis. Inilah fitur yang tidak dimiliki oleh software desain lainnya (Ciptandi, 2018).

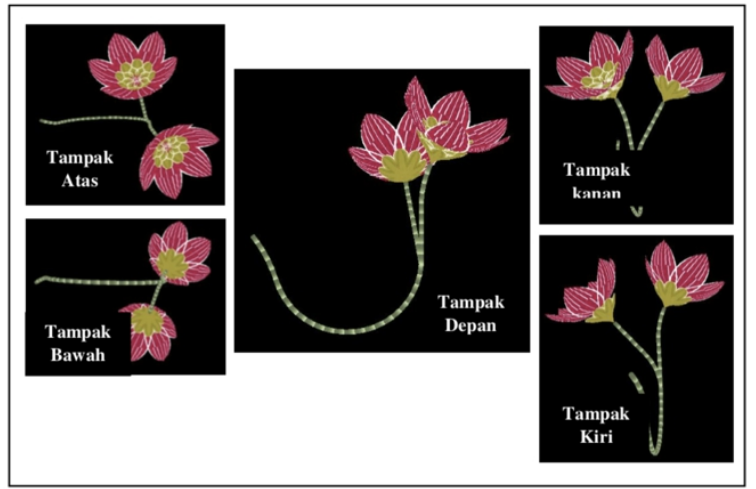

Gambar 4. Penampakan motif 3D pada softwarej Batik Pro

Hingga saat ini, aplikasi motif software jBatik selain sudah diterapkan dalam lembaran kain, juga sudah banyak 
clKh Dinamika Kerajinan dan Batik: Majalah Ilmiah. Vol. 37 No. 2, Desember 2020, hal. 135 - 146

diterapkan pada produk fashion seperti pakaian, tas, dan sepatu.

\section{METODOLOGI PENELITIAN}

Penelitian dilakukan melalui dua tahapan metode. Tahapan pertama diawali dengan pengumpulan data-data terkait bordir kerancang dan software jBatik. Lalu setelah menganalisa data tersebut, dilanjutkan dengan tahap pengembangan eksplorasi komposisi motif bordir kerancang dengan software jBatik. Hasil penelitian ini berupa komposisi bordir kerancang yang diaplikasikan pada purwarupa produk berukuran 1:1.

\section{Alat dan Bahan}

Bahan dan alat yang digunakan dalam penelitian terbagi menjadi dua bagian, bagian pertama saat proses melakukan pengembangan eksplorasi komposisi bordir kerancang, yang kedua adalah pada saat proses pembuatan pola dan purwarupa produk. Pada bagian pertama, saat membuat komposisi bordir kerancang menggunakan software jBatik Basic dan jBatik Pro. Selanjutnya pola pakaian dibuat secara manual terlebih dahulu dengan kertas roti untuk kemudian discan, hasil scan dimasukkan ke dalam software desain Corel Draw atau Adobe Ilustrator untuk dikombinasikan dengan komposisi motif bordir kerancang yang telah dibuat. Keseluruhan software dapat diinstall pada laptop atau personal computer (PC). Selanjutnya pola dicetak dengan mesin digital printing di atas kain katun kemudian dibordir menggunakan mesin jahit bordir Juki LZ-271. Pola yang sudah memiliki hasil bordir kerancang kemudian dijahit menjadi satu menjadi purwarupa produk.
Prosedur Kerja

Penelitian diawali dengan proses pengumpulan data melalui Studi literatur, yang meliputi pencarian data mengenai perkembangan teknik serta produk aplikasi bordir kerancang khususnya juga teknik bordir lainnya secara umum di kota Tasikmalaya dan kota besar di Indonesia. Perkembangan serta penggunaan software jBatik pun tidak luput untuk didalami. Studi literatur dilakukan melalui buku, jurnal, artikel ilmiah, serta artikel populer di internet. Lalu observasi lapangan dilakukan untuk mengetahui perkembangan produk aplikasi bordir, baik di dalam ataupun di luar kota Tasikmalaya. Begitupun untuk produk olahan jBatik yang sudah diproduksi hingga saat ini sehingga dapat diketahui mengenai pengembangan motif serta komposisi motif terbaru. Kemudian berikutnya adalah tahap wawancara. Setelah mendapatkan informasi mengenai perkembangan teknik serta pengaplikasiannya pada produk, baik untuk teknik bordir kerancang dan software jBatik, kemudian dilakukan tahap triangulasi data dengan mewawancarai perajin bordir serta praktisi jBatik.

Setelah semua data terkumpul, tahap selanjutnya adalah proses eksperimen yang bertujuan menghasilkan kebaruan motif serta komposisinya menggunakan software jBatik untuk kemudian diaplikasikan pada purwarupa produk. Proses eksperimen terbagi dalam empat tahapan yaitu sebagai berikut: (a) Tahap pertama adalah perancangan konsep dan moodboard. Proses ini bertujuan agar motif serta komposisi yang dihasilkan dapat lebih terarah dan memberikan kebaruan. Moodboard tetap dirancang berkaitan 
clKh Dinamika Kerajinan dan Batik: Majalah Ilmiah. Vol. 37 No. 2, Desember 2020, hal. 135 - 146

dengan karakter kota Tasimalaya. (b) Tahap kedua, perancangan motif menggunakan software jBatik Basic dan jBatik Pro, yang dikembangkan oleh perusahan Piksel merujuk pada hasil wawancara dengan $M$. Lukman (Fadliani, 2017) selaku Chief Design Officer Piksel (c) Tahap ketiga yaitu perancangan komposisi motif menggunakan software jBatik Basic dan jBatik Pro. Kemudian komposisi motif terbaik ditempatkan pada pola purwarupa produk dengan ukuran 1:1, menggunakan software desain Corel Draw atau Adobe Ilustrator. (d) Terakhir, adalah tahap perwujudan purwarupa produk dengan ukuran 1:1, agar dapat memberikan gambaran utuh bagaimana komposisi motif diaplikasikan pada purwarupa produk.

\section{HASIL DAN PEMBAHASAN}

Perwujudan purwarupa produk diawali dengan tahapan pertama yaitu perancangan konsep dan moodboard. Berdasarkan hasil observasi, salah satu produk aplikasi bordir kerancang yang banyak diminati adalah kebaya, khususnya kebaya encim. Oleh karena itu, purwarupa produk yang akan dikembangkan adalah kebaya dengan tema konsep yang akan diangkat dalam penelitian ini adalah Cleonix. Cleonix adalah permainan kata yang merujuk pada inspirasi utama perancangan motif yang akan dikembangkan, yaitu motif bunga chrysanthenum, bunga lotus, dan phoenix. Motif phoenix sendiri hanya akan diambil bagian khasnya saja, seperti pada bagian sayap, agar menyesuaikan dengan karakter bordir Tasikmalaya yang tidak mengangkat makhluk bernyawa pada desain motifnya (Putrie \& Hosiah, 2012) (lihat Gambar 5).

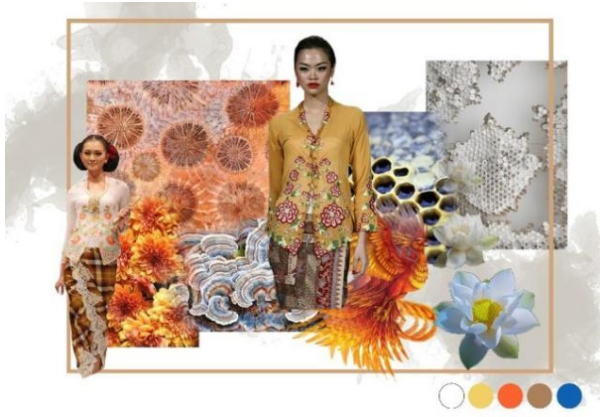

Gambar 5. Moodboard"Cleonix"

Komposisi warna menggabungkan warna lembut namun memiliki warna motif yang bold atau terang sesuai dengan karakter persilangan kebudayaan Indonesia, Belanda, dan Cina (Lukman et al., 2013). Oleh karena itu memilih kombinasi warna putih, jingga, dan biru sesuai dengan warna inspirasi bentuk motif yang diambil.

Tahap kedua adalah perancangan motif. Motif dikembangkan dari setiap elemen yang membangun moodboard menggunakan software jBatik Basic dan jBatik Pro. Motif awal diambil dari kumpulan motif dasar yang disediakan dalam software jBatik Basic, lalu kemudian dilakukan proses pengembangan motif dengan pengulangan berbagai ukuran, jarak, lengkungan, serta mengatur sudut pandang. Memanfaatkan semua fitur dalam kedua software tersebut (lihat Gambar 6).

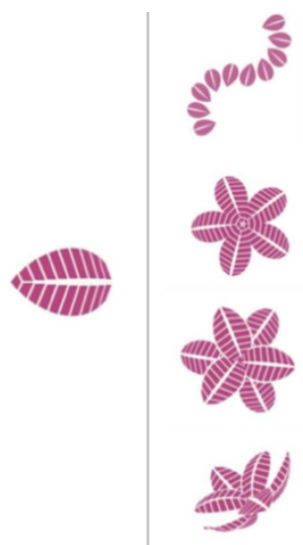

Gambar 6. Hasil pengembangan motif dasar menggunakan software jBatik 
clKh Dinamika Kerajinan dan Batik: Majalah Ilmiah. Vol. 37 No. 2, Desember 2020, hal. 135 - 146

Setelah membuat eksperimen berbagai motif dasar, motif kemudian dikategorikan menjadi tiga tipe yaitu motif utama, motif pendukung, dan motif aksen (Rosandini \& Syafrudin, 2017) dan dipilih motif yang terbaik untuk dilanjutkan pada tahap perancangan komposisi motif (lihat Gambar 7).

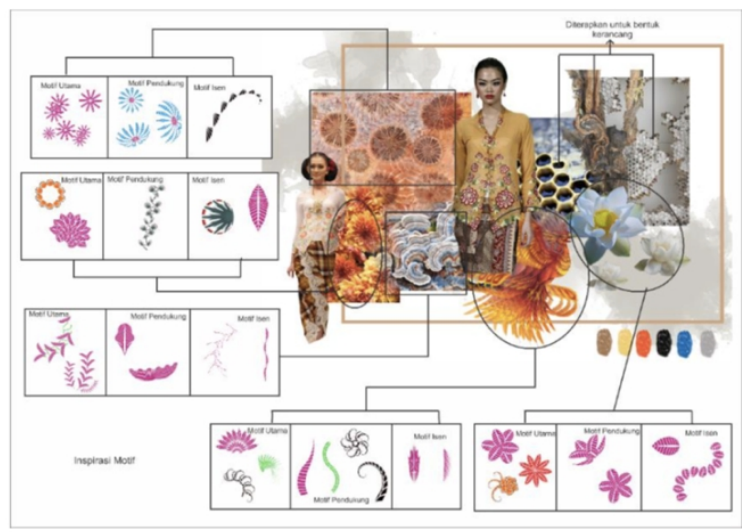

Gambar 8. Hasil pengaplikasian komposisi motif ke-1 pada desain pola
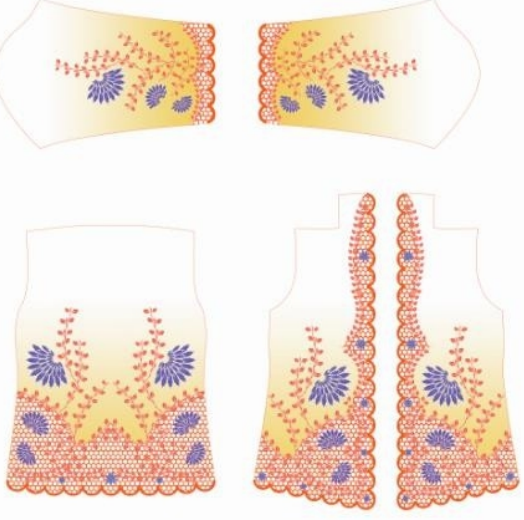

Gambar 7. Perancangan motif berdasarkan moodboard"Cleonix"

Tahap ketiga adalah perancangan komposisi motif dan pengaplikasiannya pada pola purwarupa produk. Proses perancangan komposisi motif dilakukan melalui software jBatik. Kemudian hasil komposisi motif ditempatkan dalam pola kebaya dan dilakukan penyesuaian desain melalui software Corel Draw atau Adobe Ilustrator. Hasilnya dapat dilihat pada Gambar 8, Gambar 9, Gambar 10, Gambar 11.

Gambar 9. Hasil pengaplikasian komposisi motif ke-2 pada desain pola
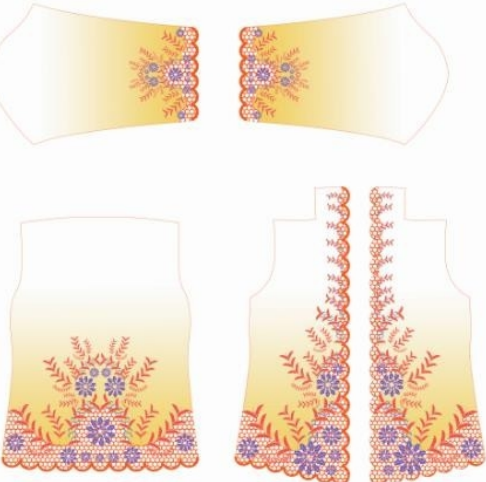

Gambar 10. Hasil pengaplikasian komposisi motif ke-3 pada desain pola 
clKh Dinamika Kerajinan dan Batik: Majalah Ilmiah. Vol. 37 No. 2, Desember 2020, hal. 135 - 146

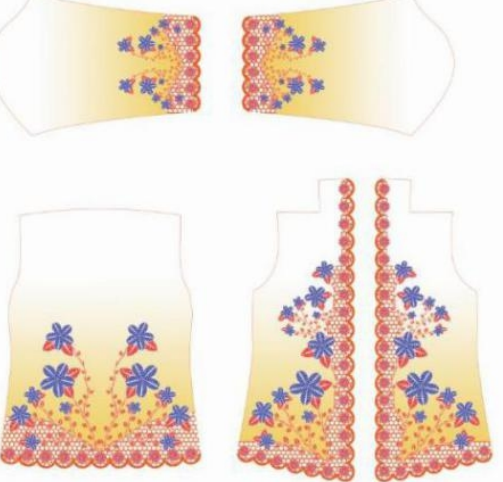

Gambar 11. Hasil pengaplikasian komposisi motif ke-4 pada desain pola

Tahap terakhir yaitu perwujudan purwarupa produk. Desain pola yang sudah dibuat kemudian diprint pada lembaran kain katun menggunakan teknik printing sublime. Setelah diprint, pola digunting untuk selanjutnya dibordir mengikuti desain komposisi yang telah dibuat dan dijahit menjadi purwarupa produk (lihat Gambar 12). Tidak perlu lagi menjiplak motif ke atas kain

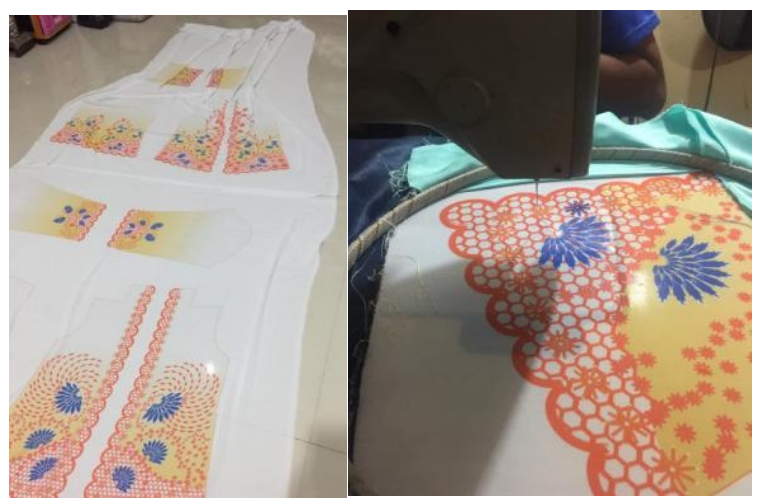

Gambar 12. Komposisi motif dan pola yang sudah diprinting di atas kain

Dalam proses yang lebih sederhana, proses printing sublime pada lembaran kain dapat diganti dengan mencetak komposisi motif pada lembaran kertas minyak atau kertas kalkir. Kemudian dilakukan proses pemindahan desain secara manual ke atas kertas, untuk selanjutnya langsung ditimpa dengan bordir, atau digambar ulang bahkan dijadikan cetakan (Loita \& Husen, 2018). Hasil purwarupa produk 1:1 yang dihasilkan dapat dilihat pada Gambar 13, Gambar 14, Gambar 15, dan Gambar 16.
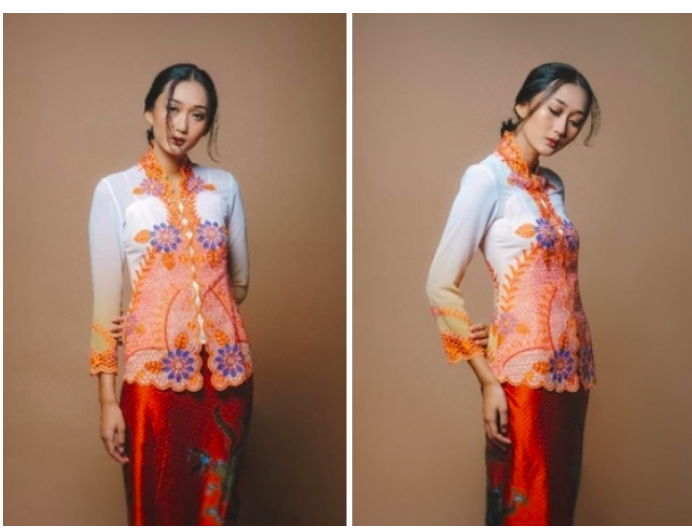

Gambar 13. Purwarupa produk hasil komposisi motif ke-1

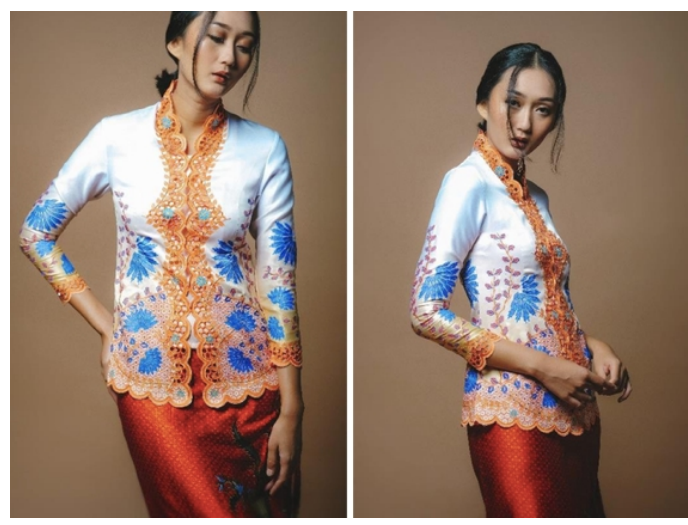

Gambar 14.Purwarupa produk hasil komposisi motif ke-2

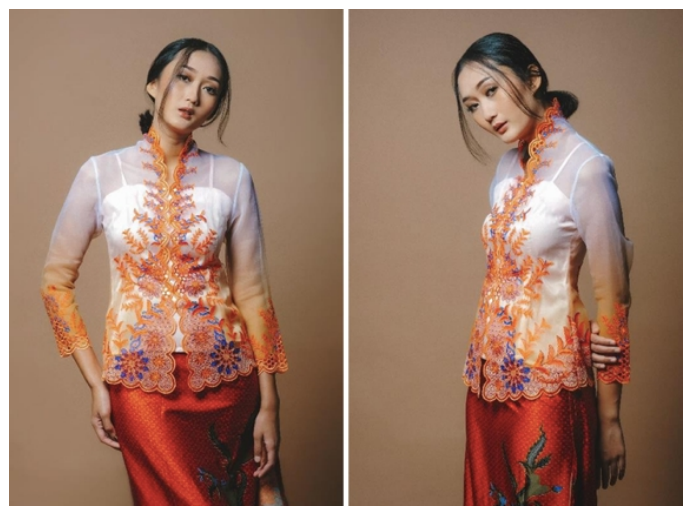

Gambar 15.Purwarupa produk hasil komposisi motif ke-3 
clKh Dinamika Kerajinan dan Batik: Majalah Ilmiah. Vol. 37 No. 2, Desember 2020, hal. 135 - 146

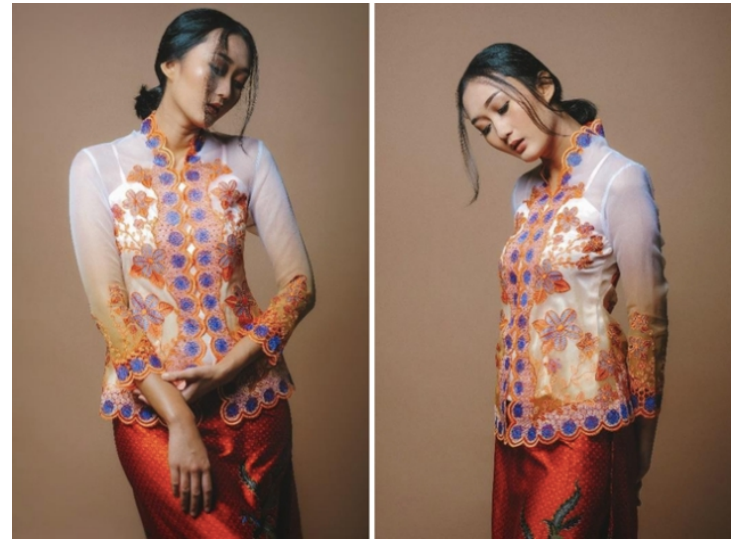

Gambar 16 Purwarupa produk hasil komposisi motif ke-4

\section{KESIMPULAN DAN SARAN}

Kesimpulan

Dengan fitur yang ditawarkan oleh software jBatik, pengrajin akan sangat terbantu dalam proses perancangan motif dan komposisi motif. Ketersediaan motif dasar membantu proses awal pengembangan motif menjadi lebih mudah.

Fitur utama yang ditawarkan software jBatik yaitu kemudahan pengulangan motif, perubahan ukuran motif, perubahan jarak antara motif, serta pembuatan lengkungan adalah kekuatan utamanya. Jika dibandingkan dengan software desain lainnya seperti pada Adobe IIlustrator atau Corel Draw, proses ini hanya dapat dilakukan secara manual, tidak ada fitur yang dapat membuat secara langsung dan presisi.

Software jBatik Basic dan jBatik Pro pun memiliki kelebihannya masing-masing. Namun software jBatik Pro yang menawarkan fitur motif 3D atau dapat dilihat dari berbagai sudut, memberikan kekhasannya sendiri. Yang mana kesan bentuk 3D ini sulit untuk dibuat secara manual menggunakan bantuan software desain lainnya. Selain itu, melalui software jBatik, proses penyimpanan data pun dapat dilakukan secara digital dan membuat sistem pengarsipan yang lebih baik untuk jangka panjang. Kelebihan lainnya, hasil akhir komposisi motif dan pola yang diprinting langsung di atas kain, membuat perajin dapat membuat bordir dengan lebih cepat dan presisi. Proses ini cocok untuk diterapkan dalam produksi massal. Proses perancangan motif dengan bantuan teknologi seperti ini membuat proses produksi menjadi lebih efisien dan mampu menghadirkan variasi baru. Selain itu pengaplikasian software jBatik yang selama ini masih terbatas digunakan pada perancangan batik dan ulos, nyatanya berpeluang untuk diaplikasikan pada perancangan bordir.

\section{Saran}

Dalam penelitian ini, proses desain masih dilaksanakan langsung oleh peneliti, belum diujicobakan pada perajin. Sehingga perlu ada penelitian lebih lanjut mengenai proses pengenalan dan pemakaian software kepada para pengrajin untuk melihat perbandingan hasilnya. Selain diberi pendampingan penggunaan software, ada baiknya perajin pun diberikan dasar-dasar ilmu desain.

Karakter visual motif dan komposisi motif yang dihasilkan software jBatik, walaupun dinamis masih terasa hasil komputerisasi jika dibandingkan dengan motif yang merupakan hasil goresan tangan. Perlu ada penelitian lebih lanjut untuk mengembangkan berbagai komposisi motif bordir lainnya. Begitupun dalam proses pengaplikasian, komposisi motif masih terbatas dikerjakan dengan teknik bordir kerancang saja, sehingga masih banyak peluang pengembangan yang bisa dilakukan dengan teknik bordir lainnya.

\section{DAFTAR PUSTAKA}

Chen, S., \& Zhang, H. (2018). Study on Han Embroidery Pattern of the Intangible Cultural Heritage. Advances in Social Science, Education and Humanities Research (ASSEHR), 184(ICESEM), 102-106. https://doi.org/10.2991/icesem-18.2018.23

Ciptandi, F. (2018). Traditional Batik Tuban Innovation Through Motive Development 
clKh Dinamika Kerajinan dan Batik: Majalah Ilmiah. Vol. 37 No. 2, Desember 2020, hal. 135 - 146

Uses jBatik Software. 207(3rd International Conference on Creative Media, Design and Technology (REKA 2018) Traditional), 8891. https://doi.org/10.2991/reka18.2018 .19

Darusman, Y. (2016). Kearifan Lokal Kerajinan Bordir Tasikmalaya Sebagai Ekonomi Kreatif Terbuka Untuk Modern. Journal of Nonformal Education, 2(2), 107-119. https://doi.org/10.24914/jne.v2i2.6556

Fadliani, T. N. I. (2017). Penerapan jBatik untuk Pembuatan Motif Bordir Kerancang pada Kebaya ENcim. Telkom University.

Gumulya, D., \& Octavia, N. (2017). Kajian Akulturasi Budaya pada Busana Wanita Cina Peranakan. Journal of Art, Design, Art Education And Culture Studies (Jadecs), 2(1), 12-25.

Hariadi, Y., Lukman, M., \& Destiarmand, A. H. (2013). Batik Fractal: Marriage of Art and Science. ITB Journal of Visual Art and Design, 4(1), 84-93. https://doi.org/10.5614/itbj.vad.2013.4.1.9

Heurteaux, Y., \& Jaffard, S. (2007). Multifractal Analysis of Images: New Connexions Between Analysis and Geometry. NATO Security through Science Series B: Physics and Biophysics, 1, 169-194. https://doi.org/10.1007/978-1-4020-56208-9

Lee, T. (2016). Dress and Visual Identities of the Nyonyas in the British Straits Settlements; requirements of the degree of Doctor of Philosophy. Thesis, PhD, (March 2016), 144.

Loita, A., \& Husen, W. R. (2018). VARIASI BENTUK DAN MAKNA MOTIF BORDIR DI SENTRA BORDIR KECAMATAN KAWALU KOTA TASIKMALAYA. Jurnal Pendidikan Dan Kajian Seni, 3(2), 166-179. https://doi.org/10.30870/jpks.v3i2.4579

Lukman, C. C., Piliang, Y. A., \& Sunarto, P. (2013). Kebaya Encim as the Phenomenon of Mimicry in East Indies Dutch Colonial's Culture. The International Institute for Science, Technology and Education (IISTE), $15-22$.

Nero, A., Sofianto, K., Sutirman, M., \& Suganda, D. (2019). Seni Bordir Tasikmalaya Dalam Konstelasi Estetik Dan Identitas. Patanjala: Jurnal Penelitian Sejarah Dan Budaya, 11(1), 81-95.

https://doi.org/10.30959/patanjala.v11i1.47
6

Putrie, Y. E., \& Hosiah, A. (2012). Keindahan Dan Ornamentasi Dalam Perspektif Arsitektur Islam. Journal of Islamic Architecture, 2(1), 46-51.

https://doi.org/10.18860/jia.v2i1.2106

Rosandini, M., \& Syafrudin, I. (2017). Pengolahan Motif Batik Perpaduan Unsur Tradisi Jawa dan Jepang. Jurnal Rupa, 2(2), 138-149. https://doi.org/10.25124/rupa.v2i2.1217

Yoga, W. B. S., \& Eskak, E. (2015). Ukiran Bali dalam Kreasi Gitar Elektrik. Dinamika Kerajinan Dan Batik: Majalah IImiah, 32(2), 117-126. https://doi.org/10.22322/dkb.v32i2.1367

Yolanda, N., \& Efi, A. (2019). BORDIR KERANCANG DI KOTA PAYAKUMBUH (Studi Kasus di Agnes Embroidery). Jurnal Kapita Selekta Geografi, 2(4), 70-75.

Yuliarma. (2016). The Art of Embroidery DesignsMendesain Motif Dasa Bordir dan Sulaman. In Jakarta: KPG (Kepustakaan Populer Gramedia) (1st ed.). https://doi.org/10.1145/2505515.2507827 
clKh Dinamika Kerajinan dan Batik: Majalah Ilmiah. Vol. 37 No. 2, Desember 2020, hal. 135 - 146 